\title{
doispontos:
}

\section{Intencionalidade e técnica(s)}

\author{
Márcia A. Baldissera \\ marciabaldissera@gmail.com \\ Centre de Recherches sur les Arts et le Langage (CRAL), École des Hautes Études en Sciences Sociales \\ (EHESS), Paris, França
}

Resumo: A técnica é a ação de um agente Intencional, com uma determinada finalidade, sobre específicas propriedades físicas, ação que constitui um objeto técnico. O reconhecimento desta Intencionalidade da ação dos autores da técnica é necessário para o processo de compreensão desses objetos pelos receptores, principalmente para a compreensão dos objetos técnicos caracterizados também como suportes semióticos. A minha hipótese é que essa Intencionalidade pode vir "mascarada" pela própria ação técnica constituinte da forma do objeto, e também pelo discurso institucional, dificultando a compreensão desses objetos pelo público. Trata-se também de esclarecer quais as propriedades que são realmente ontológicas nos objetos técnicos.

Palavras-chave: Ontologia; Recepção; Forma; Searle; Schaeffer; Fenomenologia.

Abstract: A technique is an action of an Intentional agent, with a determined purpose, upon specific physical properties. This action constitutes a technical object. Identifying the Intentionality of authors' actions is necessary for the comprehension of these objects by receivers, particularly for the comprehension of technical objects which are also characterized as semiotic supports. My hypothesis is that this Intentionality can be "disguised" by the technical action itself, particularly in questions of form, and also by institutional discourse, which problematizes the comprehension of these same objects by the public. It will be a matter as well of clarifying the ontological properties of technical objects.

Keywords: Ontology; Reception; Form; Searle; Schaeffer; Phenomenology.

A Intencionalidade é uma propriedade mental inata que possibilita nossa relação às coisas e aos estados de coisas do mundo. A ação que se caracteriza como técnica é intencional e Intencional; e pode também ser dotada de Intencionalidade, caracterizando por sua vez os objetos técnicos como um suporte semiótico. O reconhecimento desta Intencionalidade da ação dos autores da técnica é necessário para o processo de compreensão desses objetos. Mas, essa mesma Intencionalidade pode vir "mascarada" pela própria ação técnica constituinte da forma do objeto, e também pelo discurso institucional, dificultando a compreensão desses objetos pelos sujeitos receptores.

Para demonstrar essa hipótese, partirei da noção de Intencionalidade em Searle, sem entrar no debate filosófico sobre a sua relação à consciência e ao mental, ou da relação entre filosofia da mente e filosofia da linguagem. Em seguida, tratarei da questão das ações Intencionais e das ações dotadas de Intencionalidade, que podem caracterizar os objetos técnicos. A questão das ações dotadas de Intencionalidade colocará o problema das condições de satisfação do significado que, enfim, será desenvolvido através da análise da relação entre a Intencionalidade autoral, a forma de exteriorização do objeto e o "Cenário" ou Background do(s) receptor(es). 


\section{INTENCIONALIDADE}

A Intencionalidade é a propriedade de certos estados e eventos mentais de referir-se a alguma coisa, de ser sobre alguma coisa, de estar para alguma coisa, ou seja, de representar um objeto através de um conteúdo Intencional. A origem etimológica da palavra é o verbo latino tendere, que indica a ideia de direção ou tensão. A Intencionalidade reflete então uma perspectiva sobre o seu objeto. Esta característica confere à Intencionalidade uma "forma aspectual" (aspectual shape), enquanto toda representação mental possui certos aspectos precisos provenientes da perspectiva do sujeito em relação ao objeto em um determinado momento, e não quaisquer ou todos os aspectos possíveis da relação sujeito-objeto (SEARLE, 1992, p. 131). Assim, todo estado Intencional é composto por um conteúdo, em um determinado estado psicológico, que representa um determinado objeto em uma determinada forma aspectual, que, juntos, determinam as condições de satisfação deste conteúdo Intencional. Estas condições de satisfação são também relativas ao "Cenário" (Background) do sujeito, que consiste nas capacidades, habilidades, conhecimentos (perceptivos, práticos, procedurais, etc.), que permitem o funcionamento dos nossos estados mentais. O Background não é Intencional, mas ele é o suporte para a "Rede" (Network) de estados Intencionais poderem realizar-se (SEARLE, 1992). Ainda, os estados e os eventos Intencionais podem ser conscientes ou pré-conscientes, ou seja, podem ser acessíveis à consciência em diferentes níveis, mas Searle rejeita a ideia que os estados e os eventos Intencionais possam ser inconscientes.

Algumas distinções merecem ser feitas, mesmo que rapidamente. Em primeiro lugar, Searle utiliza a letra I maiúscula para visualmente distinguir a noção de Intencionalidade do conceito de intenção. A Intencionalidade caracteriza grande parte dos nossos estados mentais, tais como as crenças, conhecimentos, emoções, etc., que não podem ser reduzidos ao estado mental de querer fazer alguma coisa. Enquanto a Intencionalidade estabelece uma relação de fazer referência $a$, a intenção estabelece uma relação de vontade, de desejo (SCHAEFFER, 1996, p. 65). Assim, toda intenção é também Intencional, mas não o contrário.

Em segundo lugar, além de certos estados mentais, a Intencionalidade também caracteriza os eventos mentais primários: a percepção e a ação. Primários no sentido de serem os processos cognitivos fundamentais da nossa interação com o mundo, enquanto a percepção e a ação envolvem o nosso organismo em relações causais diretas com o ambiente; ou seja, as propriedades físicas da situação têm um papel causal nessas experiências que constituem a percepção e a ação. Assim, a percepção e a ação distinguem-se dos estados Intencionais porque são eventos que se desenvolvem em um determinado ambiente e em uma determinada dinâmica, e que, portanto, possuem um caráter fenomenológico importante. Quer dizer, entre as condições de satisfação desses eventos Intencionais, a forma aspectual tem também um papel causal nessas experiências, ainda que essa forma aspectual da Intencionalidade não seja relativa ao objeto, mas, sim, relativa à experiência na qual se desenvolve a relação sujeitoobjeto. Podemos ter experiências diferentes com o mesmo objeto. Em consequência da relação causal com o ambiente, é necessário distinguir entre possíveis causas nesses eventos. A percepção é causada pela experiência perceptiva das propriedades físicas do seu objeto; a ilusão, ao contrário, é causada pela experiência perceptiva das propriedades fenomenais da própria experiência, porque a causa deste estado Intencional não corresponde efetivamente às propriedades físicas do objeto; enquanto a alucinação é causada pela experiência perceptiva de um estado Intencional, isto é, uma crença. Uma queda pode ser causada por um evento físico, por uma ação sem uma intenção prévia, ou pode ter uma causa Intencional. Por exemplo, um sujeito está andando de skate, desequilibra-se e cai. No caso de uma ação envolvendo um 
agente Intencional, precisamos distinguir entre a "intenção prévia" e a "intenção em ação" propriamente dita. Nem toda ação contém uma intenção prévia, ou seja, é causada por uma intenção, mas toda ação contém uma intenção em ação, pois toda ação é um fazer alguma coisa, é uma "performance", e, para Searle, todo fazer tem um propósito, uma finalidade (SEARLE, 1983, p. 107). A queda representa uma intenção em ação, independentemente da sua causa. Para que uma intenção em ação seja uma ação Intencional, é necessário que esta ação seja a condição de satisfação do seu conteúdo Intencional. Ou seja, no caso da queda do skate, se esta ação tem como conteúdo Intencional a queda, a intenção prévia é cair, então a queda tem uma causa Intencional, como no caso em que a queda do skate é uma representação teatral, ou mesmo uma farsa.

O fazer técnico é uma ação Intencional. É uma ação que tem um determinado propósito original, e esse propósito original é também o conteúdo Intencional desta ação, ou seja, uma representação mental de um fazer técnico (fazer $\mathrm{x}$ valendo-se de determinados procedimentos, como, por exemplo, tecer, esculpir, colorir, sambar, construir, contar uma história, representar uma figura, tocar um instrumento, etc.). Essa ação, que realiza um determinado conteúdo Intencional, envolve também uma determinada perspectiva subjetiva que, juntos, determinam as condições de satisfação dessa experiência - fazer $\mathrm{x}$ de tal e tal maneira - que, como vimos, são relativas ao Background deste sujeito. Devemos lembrar também que o fazer técnico é um evento que implica, na verdade, uma série de gestos e de atos perceptivos na relação com o objeto. Os procedimentos da ação técnica colocam em relação algumas propriedades físicas dando-lhes uma unidade formal, uma estrutura, de caráter funcional, e, em muitos casos também de caráter expressivo. Estes procedimentos podem, em diferentes etapas do processo, seguir ou não regras estabelecidas. E esta experiência pode também atualizar ou mesmo renovar o conteúdo Intencional original.

Uma das principais objeções a uma teoria "forte" da intencionalidade autoral dos objetos "artísticos", forte no sentido de ser a condição necessária e suficiente para a compreensão do objeto, seria a importância dada ao "mental" em detrimento do objeto físico. Um objeto pode representar muito mais do que a intenção do seu autor. Nelson Goodman foi um dos maiores críticos a esse respeito, enfatizando, precisamente, que a atenção não pode ser desviada da análise do funcionamento desses objetos. $\mathrm{Na}$ verdade, esta objeção é amplamente aceita, o que não impede de aceitar-se também uma teoria "moderada" da intencionalidade autoral, isto é, "moderada" enquanto necessária, mas não suficiente. Por exemplo, Jerrold Levinson a define como "intencionalismo hipotético", afirmando que não é sempre possível conhecer a real intenção do(s) autor(es), mas é necessário realizar inferências sobre essa intenção a partir do próprio objeto, da história da sua técnica artística e da história do próprio autor. Já Michael Baxandall, utilizando o termo "intenção processual", ressalta que reconhecer a intenção do autor não significa fazer sua interpretação psicológica, mas dar-se conta dos meios a sua disposição e dos fins pretendidos inscritos no objeto. (cf. COMETTI, MORIZOT \& POUIVET, 2000). Jean-Marie Schaeffer, que pensa a questão da Intencionalidade autoral a partir de Searle, argumenta a favor de uma teoria "moderada" da seguinte maneira:1) uma parte das propriedades do objeto não pode ser explicada como sendo de causalidade Intencional, pois algumas propriedades têm uma causalidade física: eventos físicos e processos mentais inconscientes, como a estimulação dos órgãos sensoriais e a transmissão nervosa às áreas cerebrais, por exemplo; 2) outras propriedades são causadas intencionalmente, ou seja, não representam um conteúdo Intencional porque são relativas ao Background: capacidades, habilidades, conhecimentos, como a manualidade de um ceramista, por exemplo. Mas, teoricamente, mesmo essas propriedades intencionais poderiam ser "reconstruídas" através da análise da sequência das ações intencionais que as produziram; e 
3) a intenção que sustenta as ações técnicas é uma "intenção processual":

$[N]_{o}$ decorrer do processo de criação, a intenção em ação se modifica continuamente pelo fato que uma ação entra em uma relação de causa-efeito entre a gestação e a estrutura da obra, e então também em relação ao conteúdo Intencional da ação criadora, em um movimento de adaptação recíproca dos propósitos e dos meios, que restam em parte processos não ligados a experiências conscientes. (SCHAEFFER, 1996, p. 73) ${ }^{1}$

Schaeffer insiste na necessidade de reconhecer-se a Intencionalidade da experiência de criação como um processo, processo que tem um desenvolvimento particular, um feedback entre sujeito e objeto, com seus vários níveis de consciência.

De fato, a compreensão de um objeto não pode prescindir do seu nível de coisa, da sua constituição física, enquanto estas propriedades físicas são causais em relação à percepção deste objeto. A condição de satisfação primária da percepção é que os estímulos sensoriais apreendidos sejam provenientes das propriedades físicas do objeto. E a condição de satisfação da experiência perceptiva é que o aspecto fenomenológico dessa relação, ou seja, o espaço-tempo no qual estão inseridos sujeito e objeto, seja constituinte da própria experiência. A percepção, como a ação, são eventos, são processos cognitivos que têm uma extensão e uma dinâmica temporais, o que vale tanto para a criação quanto para a recepção de um objeto. Além disto, os objetos técnicos também podem se apresentar com sua própria extensão e dinâmica temporal, determinando também o ritmo da experiência perceptiva e, em consequência, o desenvolver-se dos processos cognitivos.

A compreensão é um processo tão complexo quanto a estrutura do seu objeto. Podemos, a partir de Jean-Marie Schaeffer (SCHAEFFER, 1996), distinguir ao menos três níveis do processo cognitivo que assegura a compreensão: 1) o nível das propriedades físicas do objeto ou do evento, ou seja, da percepção dessas propriedades - da apreensão sensível, da eventual identificação e categorização dessas propriedades; 2) o nível das "propriedades intencionais", ou seja, da percepção das relações entre as propriedades físicas e do reconhecimento da função, do uso, desse objeto ou evento; e 3) o nível da compreensão, da relação entre essas propriedades físicas e intencionais com a Intencionalidade autoral, ou seja, do reconhecimento da relação entre a causa Intencional e os meios e fins e, em modo muito sucinto, da avaliação implícita por parte do sujeito receptor da "coerência" ou da "incoerência" desse objeto ou evento. Este último nível tende a ser menos intenso quanto maior é o reconhecimento do caráter utilitário do objeto. Enquanto no caso de objetos que são também uma representação semiótica, deve-se inserir um nível intermediário de identificação semântica das propriedades expressivas. Todos esses níveis, mesmo se sequenciais, podem ocorrer muito rapidamente, quase que simultaneamente à percepção do objeto, dependendo da intensidade da relação sujeito-objeto, ou seja, do tipo de processo cognitivo que possa vir a desenvolver-se.

\section{AÇÕES INTENCIONAIS E AÇÕES DOTADAS DE INTENCIONALIDADE}

Searle, na introdução do seu livro homônimo, descreve que desenvolveu esta noção de Intencionalidade para dar conta da capacidade biológica inata de relacionar-se com coisas e aos estados de coisa do mundo, o que permite os atos de fala, por exemplo.

A capacidade de atos de fala para representar objetos e estados de coisas no mundo é uma extensão das capacidades mais biologicamente fundamentais da mente (ou do cérebro) para relacionar o organismo ao 
mundo por meio de estados mentais como a crença e o desejo, e em especial através da ação e da percepção. Uma vez que os atos de fala são um tipo de ação humana e uma vez que a capacidade da fala para representar objetos e estados de coisas faz parte de uma capacidade mais geral da mente para relacionar o organismo com o mundo, qualquer explicação completa da fala e da linguagem exige uma explicação de como a mente/ cérebro relaciona o organismo com a realidade. Uma vez que as sentenças - os sons emitidos pela boca ou os sinais gráficos que se fixam no papel - são, considerados de um certo modo, apenas objetos no mundo como quaisquer outros objetos, sua capacidade de representar não é intrínseca e sim derivada da Intencionalidade da mente. (SEARLE, 2002, pp. VII-VIII. Eu sublinho) ${ }^{2}$

Deste ponto de vista, (i) a Intencionalidade é a capacidade mental que sustenta a expressão e a compreensão dos atos de fala. Mas fica também claro que a mesma Intencionalidade expressiva que caracteriza um ato como ato de fala, (ii) pode caracterizar também um ato como o ato técnico, (iii) porque a expressão destes objetos físicos não é uma propriedade intrínseca desses objetos, mas, sim, uma propriedade derivada do sujeito emissor e/ou atribuída pelo sujeito receptor.

Searle diferencia entre Intencionalidade intrínseca e Intencionalidade derivada. A Intencionalidade intrínseca é característica exclusiva de certos estados e eventos mentais, enquanto a Intencionalidade derivada é a atribuição intencional de uma propriedade Intencional a objetos e eventos do mundo para dotar-lhes de sentido. O exemplo searliano é a linguagem. Mas como nota Jean-Marie Schaeffer, os objetos e os eventos dotados de Intencionalidade, isto é, que exprimem alguma coisa, não precisam necessariamente estar vinculados a um código ou convenção: a Intencionalidade pode derivar também de "universais antropológicos", como por exemplo as representações analógicas, isto é, representações que são instituídas a partir da semelhança (SCHAEFFER, 1996, p. 76). Mas nem todo ato de expressão é um ato comunicacional, do momento em que um ato comunicacional implica a compreensão efetiva do conteúdo Intencional expresso pelo emissor ao receptor.

Assim como nem todos os objetos e os eventos técnicos são dotados de Intencionalidade, enquanto as diferenças entre essas possibilidades técnicas dependem do tipo de função da ação que as origina: uma ação Intencional tem como função apenas realizar uma coisa, enquanto uma ação dotada de Intencionalidade tem uma função de realização também representacional, isto é, uma ação que também exprime um conteúdo Intencional no objeto realizado. $\mathrm{O}$ reconhecimento destas diferentes funções pelos sujeitos receptores ocorre através do paratexto, produzido pelos autores ou pelos experts (por exemplo: a propaganda, o manual de instruções, um artigo institucional, etc.), mas geralmente essas funções já foram previamente reconhecidas pela própria comunidade dos emissores e dos receptores, como é o caso de inúmeros fatos semióticos pelo mundo. Mas o que garante a efetividade deste processo cognitivo de expressão e de compreensão dos objetos e dos eventos técnicos dotados de Intencionalidade?

\section{CONDIÇÕES DE SATISFAÇÃO DO SIGNIFICADO}

A questão principal aqui, que Searle coloca de maneira simples e direta é: o que possibilita realmente a nossa capacidade de compreender as coisas e os estados de coisa do mundo? Como, muito antes do desenvolvimento de uma língua, do estabelecimento de convenções, o ser humano foi capaz de dar significado a eventos físicos como sons e traços?

Não há nada de intrinsecamente Intencional nos produtos do ato de emissão, ou seja, nos ruídos que saem 
de minha boca ou nos sinais que fixo no papel. Ora, o problema do significado, em sua forma mais geral, é o problema de como passar da física para a semântica, ou seja, como passar (por exemplo) dos sons que saem da minha boca para o ato ilocucionário? [...] [A] mente impõe uma Intencionalidade a entidades não intrinsecamente Intencionais, atribuindo intencionalmente as condições de satisfação do estado psicológico expresso à entidade física externa. (SEARLE, 2002, pp. 37-8) 3

Segundo Searle, o que garante este processo cognitivo de expressão e de compreensão dos atos de fala é a capacidade mental de atribuir um estado psicológico a uma entidade física externa. Antes de mais nada, esta é uma capacidade relacional. E no ato de reconhecer essa possibilidade da atribuição de um estado psicológico a uma entidade física externa, podemos também reconhecer essa referência a um estado psicológico de outro agente Intencional em uma entidade física externa. Ou seja, trata-se do reconhecimento da capacidade de relacionar-se com o mundo, com as coisas e os estados de coisas, com os outros agentes Intencionais, através de propriedades físicas externas, isto é, potencialmente perceptíveis. Deve-se lembrar também que a forma aspectual faz parte das condições de satisfação dos estados e dos eventos mentais Intencionais. Assim, esse estado psicológico vem acompanhado de uma forma aspectual distinta, forma aspectual que, penso, é o que efetivamente pode vir a ser percebido na entidade física externa.

Então, esta capacidade mental inata de relacionar-se às coisas e aos estados de coisas do mundo também se aplica quando percebemos os objetos e os eventos técnicos. Ou melhor, é esta capacidade mental representacional que sustenta a nossa compreensão (implícita) e a nossa interpretação (explícita) de todas as coisas do mundo. E por que parece não ser exatamente assim para todos os objetos técnicos dotados de Intencionalidade? O que ocorre, a meu ver, principalmente com os objetos da técnica audiovisual, é o não reconhecimento da Intencionalidade autoral da técnica. Penso que o problema se encontra em dotar a técnica mesma de intenção e de Intencionalidade, ou seja, de um poder de representação intrínseco, o que permite o reconhecimento da função do objeto e do seu conteúdo semântico, mas não necessariamente o reconhecimento da efetiva Intencionalidade autoral, o que pode, muitas vezes, revelar uma nova função aos objetos. Isto é, a função percebida pelos receptores pode não ser coerente com a efetiva Intencionalidade autoral representada no objeto. Por exemplo, como identificar a tênue distinção entre informação e propaganda senão através do reconhecimento da Intencionalidade autoral? "Existe significado apenas onde houver uma distinção entre o conteúdo Intencional e a forma de sua externalização" (SEARLE, 2002, p. 38) ${ }^{4}$. Ou seja, não existe significado sem a distinção da forma de exteriorização do seu conteúdo Intencional, pois esta forma determina as condições de satisfação deste conteúdo, quer dizer, o reconhecimento da forma de exteriorização do conteúdo Intencional permite o reconhecimento deste mesmo conteúdo Intencional. O mesmo conteúdo Intencional de um ato de fala, por exemplo, "São sete horas da manhã", pode ter diferentes condições de satisfação, condições de satisfação que correspondem ao estado psicológico adequado, a sua forma aspectual, e, portanto, a uma forma de exteriorização adequada que determina a sua função expressiva. Esse conteúdo Intencional pode significar literalmente que no momento do ato de fala o relógio indica sete horas, ou, expresso de outra forma, com um determinado ritmo e uma determinada melodia, pode significar o estado psicológico de uma canção e remeter ao artista, à música, ao momento histórico em questão, etc.

Se, da parte autoral, a forma de exteriorização dos objetos e dos eventos técnicos é o resultado de uma ação dotada de Intencionalidade, da parte dos sujeitos receptores essa forma de exteriorização entra em relação causal com o processo de percepção. Vale recordar que a percepção é o primeiro dos 
processos sequenciais que constituem a compreensão, além do caráter fenomenológico da experiência perceptiva. Desse ponto de vista, podemos analisar os níveis do processo de compreensão a partir, sobretudo, da sua fenomenologia. Assim, devemos ter em conta, primeiro, a fenomenologia da percepção, e em consequência, o ritmo dos objetos ou dos eventos técnicos, mas também o ritmo dos diferentes tratamentos cognitivos. Nessa sequência cognitiva, podemos então pensar na relação entre a estrutura física do objeto e a estrutura mental do seu tratamento cognitivo. Enfim, podemos também refletir sobre a questão da(s) experiência(s) de compreensão e da sua relação com o Background.

O primeiro nível da análise da técnica de um objeto deve ser a descrição das propriedades físicas desse objeto e da relação entre estas propriedades físicas, do modo como elas são efetivamente percebidas no seu ambiente e na sua dinâmica própria. Dessa maneira, é possível reconhecer o ritmo dessa experiência, ou seja, o ritmo intrínseco da percepção em relação a todo e qualquer objeto e o possível ritmo extrínseco dessa percepção quando se relaciona a um objeto temporal ou a um conjunto de objetos fixos em uma sequência, como em uma exposição ou no próprio quotidiano, por exemplo. Em termos gerais, me refiro à duração e à complexidade dos estímulos físicos e às implicações desse ritmo no desenvolvimento da experiência cognitiva de recepção dos objetos. Essas condições fenomenológicas também determinam o tipo de tratamento cognitivo e o nível de consciência dessa experiência. Em poucas palavras, trata-se da estrutura e da dinâmica dos processos cognitivos, já postuladas por Husserl e demonstradas pelos estudos da psicologia experimental e da neurociência. Determinantes para o tipo de desenvolvimento do tratamento cognitivo são a atenção e a memória de trabalho, e ambas tem um limite espaçotemporal. Além disso, o tipo de tratamento cognitivo também varia em função da interação do sujeito com o objeto. Assim, vários estudos demonstram que quanto mais tempo dura o tratamento cognitivo, mais a representação mental oriunda dos estímulos físicos se desenvolve, porque mais conhecimentos Intencionais e capacidades não Intencionais do sujeito interagem nesse processo de compreensão do objeto. Ou seja, parece-me que o reconhecimento da distinção da forma de exteriorização do seu conteúdo Intencional, condição de satisfação da compreensão desses objetos, depende também do ritmo intrínseco e/ou extrínseco da percepção desses objetos.

No desenrolar-se desse processo de compreensão, essa condição rítmica reflete-se também na relação entre a organização estrutural do objeto e a estratégia cognitiva inscrita nessa organização, ou seja, os diferentes procedimentos técnicos que criam a estrutura de um objeto implicam também em diferentes modalidades da percepção deste objeto. Quer dizer, a estrutura do objeto configura uma determinada orientação da atenção do receptor sobre uma determinada relação entre as propriedades de um mesmo nível (físicas, funcionais ou semânticas) ou sobre determinadas relações entre esses níveis. JeanMarie Schaeffer define essa estratégia da organização estrutural do objeto como o "estilo cognitivo" intencionalmente adotado pelo criador, a ser adotado também pelo receptor (SCHAEFFER, 2010). Em resumo, apoiando-se na teoria dos esquemas cognitivos de Roman Ingarden e em estudos recentes que confirmam a pertinência desses esquemas cognitivos, Schaeffer recorda que a Intencionalidade expressa em um objeto - de maneira formal, estruturada, esquemática - não se realiza senão no reconhecimento desta Intencionalidade expressa desta maneira, ou seja, o processo que assegura a compreensão de um objeto dotado de Intencionalidade nada mais é que uma esquematização dos conteúdos Intencionais do autor no modo pelo qual eles são expressos no objeto. A questão é que essa estrutura pode conter relações de analogia, de associação, de contraste, etc.; mas pode também conter relações que serão tratadas de maneira mais automática e rápida, menos atenta, como as relações causais, contíguas, repetitivas, etc. Assim como a complexidade dessa estrutura pode influir na capacidade da memória de trabalho. Ou seja, a estrutura 
formal dos objetos pode privilegiar relações que são tendencialmente tratadas automaticamente, o que resulta em um nível inferior de consciência dessas relações; enquanto outras estruturas formais podem destacar relações que desta maneira são tratadas com um nível maior de atenção, com interação sujeitoobjeto, resultando em uma consciência maior dessas relações. Portanto, o reconhecimento da distinção da forma de exteriorização do seu conteúdo Intencional depende também do reconhecimento do tipo de relação entre as propriedades físicas dos objetos e entre os níveis dessas propriedades.

Essas condições de satisfação do significado dos objetos dotados de Intencionalidade podem ser de difícil consenso, na medida em que envolvem processos mentais complexos e uma familiaridade com os estudos das ciências cognitivas. Entretanto, vale ressaltar, essas conclusões encontram respaldo em certa teoria literária contemporânea, em particular, e em alguns escritos de artistas e de teóricos de técnicas diversas, principalmente daqueles que contestavam as regras estabelecidas.

Assim, recordando certos momentos históricos de contestação da norma, que possibilitaram novas estruturas formais e novas técnicas, gostaria de finalizar essa argumentação com um fato, penso pouco contestável, porque visualmente reconhecível: a padronização estrutural de inúmeros tipos de objetos técnicos, principalmente daqueles audiovisuais, que fazem parte da nossa vida de todos os dias. Trata-se de uma questão que vai além da Intencionalidade autoral da técnica e dos fatos de cultura; trata-se de uma questão social.

"A Intencionalidade da mente não só cria a possibilidade do significado, como também limita as suas formas. $[\ldots]$ as possibilidades e limitações do significado derivam da Intencionalidade da mente" (SEARLE, 2002, p. 232) ${ }^{5}$. Creio que Searle se refere à relação de interdependência entre a Intencionalidade e o significado através do aspecto formal que os une, ou seja, as possibilidades e as limitações da forma de exteriorização do conteúdo Intencional estão diretamente relacionadas às possibilidades e às limitações da capacidade de expressá-las e de compreendê-las. Assim, acredito que um dos grandes limites das ações técnicas seja a repetição das mesmas estruturas, pois esta repetição formal representa uma limitação das nossas próprias experiências e, portanto, uma limitação da nossa capacidade de compreender as coisas e os estados de coisas do mundo.

Uma das possíveis objeções a essa hipótese sobre a repetição das estruturas físicas dos objetos e, em consequência, a repetição de estruturas cognitivas, seria a menção a certas práticas técnicas tradicionais como o teatro Nô japonês, a caligrafia chinesa, certos rituais, etc., ou até mesmo a recepção de um mesmo objeto por diversas vezes. Não se trata apenas dos próprios objetos, mas principalmente das condições para a compreensão desses objetos. O que me parece ser essencial nessa questão é refletir sobre as diferenças nas capacidades Intencionais e não-Intencionais dos sujeitos receptores, ou seja, na capacidade de expressar e compreender ao longo de inúmeras experiências. No caso dos objetos das técnicas tradicionais, cada experiência é realmente distinta, e a grande maioria dos espectadores reconhece as mínimas variações físicas, formais e expressivas desses objetos. Na verdade, trata-se de uma aprendizagem típica dos próprios autores e dos receptores experts. No caso dos objetos das chamadas arts vivants, por exemplo, os objetos também são distintos a cada experiência, mas a identificação dos mínimos detalhes físicos e das sutis relações formais e expressivas já depende de uma certa familiaridade com a técnica em questão. E o mesmo pode-se dizer quanto à recepção de um mesmo objeto diversas vezes. $\mathrm{O}$ problema da repetição, a meu ver, ocorre quando a maioria dos objetos de uma mesma técnica é praticamente idêntica estruturalmente, mesmo que aparentemente contenha conteúdos diferenciados. Ou seja, me refiro à 
ausência da detecção/apreensão de diferenças estruturais e, por conseguinte, o não reconhecimento da distinção entre a forma de exteriorização do seu conteúdo Intencional. Ao longo de inúmeras experiências, a repetição reforça uma determinada norma que se cristaliza em crença, principalmente quando o acesso a práticas diferentes desta mesma técnica é muito difícil ou inexistente. Não se trata apenas da questão da contestação de uma certa norma, mas sim da importância de se ter acesso a experiências realmente diversas desta mesma técnica. É uma questão que aponta para a importância, sobretudo, do Background: o Background dos autores e receptores experts, competentes nos seus procedimentos técnicos, e o Background dos receptores que não conseguem ter acesso a essas competências justamente porque as suas experiências não lhes fornecem essa possibilidade: falta-lhes o acesso aos diferentes procedimentos técnicos envolvidos na produção de um mesmo tipo de objeto.

O que constitui exatamente comer, o que constitui uma refeição, o que constitui um restaurante? Todas essas noções estão sujeitas a diferentes interpretações e essas interpretações não são estabelecidas pelo próprio conteúdo do estado Intencional. Além da Rede, precisamos postular um Cenário de capacidades que não são elas mesmas parte desta Rede. Ou melhor, a inteira Rede necessita de um Cenário, porque os elementos da Rede não são auto-interpretáveis ou auto-aplicáveis. (SEARLE, 1992, p. 176) ${ }^{6}$

O Background assegura as condiç̃̃es de possibilidade da própria Intencionalidade. Certas aprendizagens, procedurais, perceptivas, práticas, que provêm das experiências, correspondem ao Background. E esta competência adquirida, por sua vez, eleva as capacidades Intencionais de expressão e de compreensão dos sujeitos (SEARLE, 1992, pp. 195-6). Ou seja, nós aprendemos a reconhecer, pelas experiências de percepção e de ação, as diferentes maneiras, as diferentes possibilidades de uma determinada técnica. Um limite nessas experiências implica necessariamente um limite na capacidade da sua compreensão.

Além do Background, podemos também pensar no papel que o próprio Network de estados mentais Intencionais (crenças, desejos, conhecimentos, etc.) exerce no reconhecimento das formas de exteriorização. E principalmente refletir sobre a origem desses estados Intencionais. A esse propósito, Searle postula a noção de "Intencionalidade coletiva" (SEARLE, 1995), para dar conta do contexto intencional coletivo ou institucional que constitui em grande parte as nossas crenças, as nossas expectativas, os nossos conhecimentos. Ou seja, a nossa relação aos objetos técnicos não é independente do discurso das instituições, sejam elas acadêmicas, culturais, governamentais, industriais, etc. O que me parece ser o caso, é que o discurso consensual, porque oriundo de grande parte das instituições que têm um poder de transmissão muito forte, é um discurso que aponta, implícita ou explicitamente, para a existência de propriedades expressivas intrínsecas da técnica em geral. Trata-se de um discurso que avalia os objetos de um ponto de vista funcional através das suas propriedades semânticas, sem dar conta dos procedimentos técnicos que garantem efetivamente essa expressividade. Muito menos esse discurso explicita as possibilidades e as diferenças de um fazer que aplica uma certa técnica e das diferentes funções implicadas nesses procedimentos. Em poucas palavras, o discurso consensual aponta para conteúdos expressivos, o que também reforça a dicotomia forma-conteúdo, na medida em que ignora a estrutura formal dos objetos. Ora, a oposição forma-conteúdo não é absolutamente pertinente. Trata-se de uma relação de interdependência entre forma e conteúdo que deve sim ser distinta para que se reconheça a sua própria expressividade. Além disso, é somente a partir dessa distinção entre forma e conteúdo que se pode reconhecer a causalidade da Intencionalidade autoral e, assim, o efetivo conteúdo Intencional dos objetos técnicos. 
Em suma, no que tange à teoria e à crítica acadêmicas, parece-me necessário refletir sobre a importância da distinção entre a forma de exteriorização e o conteúdo Intencional dos objetos técnicos. Não se trata da qualidade da avaliação dos objetos técnicos por parte desses discursos, mas sim da explicitação dos meios técnicos através dos quais se pode chegar a tal avaliação, do esclarecimento dos procedimentos técnicos implicados e, em consequência, do fornecimento de instrumentos para a compreensão desses objetos pelos sujeitos.

\section{NOTAS}

1 ... au cours du processus créateur, l'intention en action se modifie sans cesse du fait d'une action en retour de la structure de l'oeuvre en état de gestation vers sa cause, et donc aussi vers le contenu Intentionnel de l'action créatrice, cela dans un mouvement d'adaptation réciproque des buts et des moyens qui repose en partie sur des processus non liés à des expériences conscientes. (tradução nossa)

2. The capacity of speech acts to represent objects and states of affairs in the world is an extension of the more biologically fundamental capacities of the mind (or brain) to relate the organism to the world by way of such mental states as belief and desire, and especially through action and perception. Since speech acts are a type of human action, and since the capacity of speech to represent objects and states of affairs is part of a more general capacity of the mind to relate the organism to the world, any complete account of speech and language requires an account of how the mind/brain relates the organism to reality. Since sentences - the sounds that come out of one's mouth or the marks that one makes on paper - are, considered in one way, just objects in the world like any other objects, their capacity to represent is not intrinsic but is derived from the Intentionality of the mind. (SEARLE, 1983, p. VII)

3. There is nothing intrinsically Intentional about the products of the utterance act, that is, the noises that come out of my mouth or the marks that I make on paper. Now the problem of meaning in its most general form is the problem of how do we get from the physics to the semantics; that is to say, how do we get (for example) from the sounds that come out of my mouth to the illocutionary act? [...] The mind imposes Intentionality on entities that are not intrinsically Intentional by intentionally conferring the conditions of satisfaction of the expressed psychological state upon the external physical entity. (SEARLE, 1983, p. 27)

4. Meaning exists only where there is a distinction between Intentional content and the form of its externalization. (SEARLE, 1983, p. 28)

5. The Intentionality of the mind not only creates the possibility of meaning, but it limits its forms. [...] the possibilities and limitations of meaning derive from the Intentionality of the mind. (SEARLE, 1983, pp. 166-7)

6. What exactly constitutes eating, what constitutes a meal, what constitutes a restaurant? All of these notions are subject to different interpretations, and these interpretations are not fixed by the content of the Intentional state by itself. In addition to the Network, we need to postulate a Background of capacities that are not themselves part of that Network. Or rather, the whole Network stands in need of a Background, because the elements of the Network are not self-interpreting or self-applying. (tradução nossa)

\section{REFERÊNCIAS}

COMETTI, J.-P.; MORIZOT, J. \& POUIVET, R. 2000. Questions d'esthétique. Paris: PUF.

SCHAEFFER, J.-M. 1996. Les célibataires de l'Art: Pour une esthétique sans mythes, Paris: Gallimard.

2010. Esthétique et styles cognitifs : le cas de la poésie. In: Critique, Paris, n 752-753, pp. 59-

$70,2010 / 1$.

SEARLE, J. 1983. Intentionality. An essay in the philosophy of mind. Cambridge, MA: CUP. In: SEARLE, 
J. 2002. Intencionalidade, $2^{\mathrm{a}}$ ed. São Paulo: Martins Fontes.

1992. The Rediscovery of the Mind. Cambridge, MA: MIT Press. In: SEARLE, J. 1997. A Redescoberta da mente. São Paulo: Martins Fontes.

. 1995. The Construction of Social Reality. New York: The Free Press. 